\title{
The Effect of Experimental Presentation of Images of Women in Magazine Advertising and Works of Art on Body (Dis)satisfaction in Adolescent Girls
}

All art originates in the human mind, in our reactions to the world rather than in the visible world itself

E.H. Gombrich, 1984, p. 71

\begin{abstract}
The present study was the first to investigate the influence of artistic images of women on adolescent girls' body attitude. The results have shown that a 10 minute exposure to artistic images of women by such great masters as Titian, Botticelli or Degas significantly changed body attitude in teenage girls, which was expressed through increased body satisfaction, decreased body dissatisfaction, and weakening of negative body emotion. Those outcomes have also confirmed the results of the existing studies exploring the negative influence of magazine advertising on teenage girls' body experiencing. The comparison of two study groups has shown that girls looking at women in works of art expressed a significantly higher level of body satisfaction than girls exposed to women in advertisements.
\end{abstract}

\section{Keywords:}

body (dis)satisfaction; images of women; media influence; perception of art; adolescence.

1 Department of General and Clinical Psychology, Faculty of Pedagogy and Psychology, University of Bialystok, Poland, E-MAIL: beatamir1@wp.pl. 


\section{INTRODUCTION}

During the adolescence period, when a significant body transformation takes place and the body gains feminine or masculine attributes, girls' and boys' preoccupation with their own body becomes very intense (Smolak, 2004). Its most common effect is dissatisfaction with one's external appearance, which can be experienced as dissatisfaction with oneself (Eisenberg et al., 2006; Knauss et al., 2008; Presnell et al., 2004). There is a risk that the process of identity shaping will be dominated by the processes of shaping the silhouette and external looks (Markey, 2010). This could signify that the key question of this developmental period: "Who am I and who do I want to be?" will be replaced by the question "How do I look and what kind of body do I need to have?”. The answer to the latter question is provided by mass media in a rather oppressive manner. They impose a model of female beauty - a woman perfect in her shape and proportions, slender, ever young, and hence unrealistic (Melosik, 1996; Tiggemann \& Slater, 2004). Media-created portraits of women activate and intensify the processes of comparison with the presented ideals of feminine beauty and of the desire to look like them (Smolak, 2004; Tiggemann, 2005). In consequence, they amend body awareness, reducing it in a significant degree to an objective dimension (Friedrickson \& Roberts, 1997; Lindberg et al., 2006).

Even though during recent decades many studies have been conducted with the purpose of exploring mass media influence, and more specifically the influence of presented idealised images of women on body image in teenage girls (Ferguson, 2013; Hargreaves \& Tiggemann, 2004; Knauss et al., 2007), the answer to the following question still remains unknown: What kinds of images of women and which ways of their presentation do not objectify body awareness? Do artistic presentations of women and of feminine beauty (which were the only forms of exposition of images of women until the invention of photography in 1839, and more specifically until the beginning of the 20th century, when colour photography appeared) also have significant meaning in shaping the relation with the body and influence the experiencing of (dis)satisfaction with one's own body and physical appearance? Can the perception of works of art presenting women as seen by great masters, such as Leonardo da Vinci or Sandro Botticelli, constitute a source of aesthetic impressions and experiences that would have positive influences on the way of experiencing their own body by 21st century teenage girls? 


\section{BODY (DIS)SATISFACTION IN ADOLESCENCE}

Body dissatisfaction is a subjective and negative opinion of the size and shape of one's own silhouette and body parts, combined with emotional tension. It is significantly different from the incapacity to adequately perceive the body size and shape that characterises people with diagnosed eating disorders (APA, 1994; Presnell et al., 2004). As a cognitive schema, body dissatisfaction consists of three components: 1) idealisation of slimness and body shape, 2) irrational fear of being fat, and 3) conviction that weight and body shape (physical appearance) are the main determinants of self-esteem and of the identity of the subject (Levine \& Murnen, 2009).

Dissatisfaction with their own physical appearance is a basic characteristic amongst teenagers. Around $60 \%$ of girls and $30 \%$ of boys declared a desire to change the shape and size of their body, while in $25 \%$ of girls this dissatisfaction reached the level of a clinical disorder (Knauss et al., 2008; Presnell et al., 2004). The socio-cultural pressure put on physical appearance causes a dramatic growth of dissatisfaction in teenagers during adolescence (Jones, 2004; Jones \& Crawford 2005; Markey, 2010; Rosenblum \& Lewis, 1999). A prevailing majority of teenage girls, when confronted with beauty ideals imposed by society, suffer disappointment and dissatisfaction with their own silhouette. This dissatisfaction is often broadened to concern other than solely physical parts of the self. This onerous problem is experienced by around $80 \%$ of the female population (Polivy \& Herman, 2002). Given the prevalence of this phenomenon, it was named "normative discontent” (Rodin et al., 1985).

\section{MEDIA AND BODY (DIS)SATISFACTION}

Most researchers agree that body dissatisfaction was shaped by, and has been maintained under the significant influence of socio-cultural impacts, especially the media (Tiggemann \& Slater, 2004). The media trigger the internalisation processes of beauty ideals that lead to the subject's treating them as his/her own - he or she identifies with them and wants to reach them at all costs. The stage of reaching the idealised slim silhouette becomes a criterion of self-esteem, a determinant of sense of security, as well as of satisfaction with the self and with one's own life (Thompson et al., 1999). Women are exposed to media influence much earlier than men (Jones, 2004).

Research indicates that the intensity of contact with media messages closely correlates with the quality of the body image of their receivers. For example, the 
perception of one's own body shape changes in a very clear way after a 30-minute reception of television messages involving an ideal of beauty (Myers \& Biocca, 1992). This influence is especially strong and significant in women below 19 years of age (Groesz et al., 2002). Watching obese and average-weight women does not influence the manner of evaluating media addressees' physical attractiveness (similarly to watching neutral objects, such as cars, houses, etc.). On the other hand, the exposition of slimness ideals negatively influences the experiencing of body-related emotions - it intensifies fear, shame and the feeling of body dissatisfaction (Dittmar \& Howard, 2004). Moreover, it increases sensitivity to one's own external looks and body self-awareness (Fredrickson \& Roberts, 1997; Kilbourne, 2002). The negative effect of media images is stronger in women, who are characterised by higher levels of internalisation of social slimness standards. When the internalisation level is very high, watching images of perfect women motivates and cognitively prepares the media message receivers for more intense thinking about themselves in terms of weight, shape and physical beauty (Halliwell \& Dittmar, 2006). Recent meta-analyses have concluded that media ideals of women across both correlational and experimental designs are generally minimal and limited to those with pre-existing body dissatisfaction (Ferguson, 2013).

\section{OBJECTIFIED BODY CONSCIOUSNESS}

The objectifying culture (the so-called "culture of physical appearance") causes people to learn such a self-perception as if they were external observers. They engage more in "external existence" than in self-experiencing. Hence, they increase the level of body self-awareness as an object, at the same time losing contact with their experiences, emotions and needs (McKinley \& Hyde, 1996). Under the influence of the growing self-awareness of one's own appearance, the following begin to dominate: 1) fear, and 2) body shame (Fredrickson \& Roberts, 1997). The shame triggers an immense desire to hide, to escape other people's looks, as well as a feeling of worthlessness and powerlessness (Lewis, 1992). It constitutes a motivation to undertake the effort of changing one's body (e.g. through diet, intense physical exercise, or even surgical interventions). It is especially during the period of adolescence that the susceptibility of girls to the process of body objectification takes place (Fredrikson \& Roberts, 1997; Martin \& Gentry, 1997). 


\section{PERCEPTION OF WORKS OF ART}

A work of art is a special stimulus (the so-called "superstimulus") which triggers a strong perceptive-emotional reaction in the receiver (Ramachandran \& Hirstein, 1999). Subtle aesthetic emotions are released thanks to complex techniques employed by the artist. This includes all sorts of exaggeration, omission, or shift of composition, which makes the identification of the painting's meaning more complicated than in the case of an explicit photograph (Ramachandran, 2011). When looking at a work of art, the modules responsible for associative memory have bigger difficulties juxtaposing new information arriving from the sensory canal with the pre-accumulated memory data. This means that the visual system, when confronted with a piece of art, is forced to go beyond the standard reception and examine it through an intense perceptive interpretation. The ambiguity and complexity of a work of art cause the subject to actively experience the analysis of the painting, formulating a number of hypotheses, which - when positively verified - are rewarded. This effect (the so-called “rewarding” impression) is caused by the activation of the limbic system - its reflexive connections to the visual cortex consolidate and stabilise the recognised object (Ramachandran, 2011; Zeki, 2004). It is especially the technique of exaggeration (for example in shapes, anatomic postures, colour, depth, movement) that triggers a strong emotional-aesthetic reaction. According to Ramachandran and Hirstein (1999), the brain probably contains neurons that represent qualities of a female body, the perceptive fields of which react to exaggerated shapes. Artistic representations of women in works of art (as "superstimuli") strongly stimulate those neurones, which, in return, intensively activate the emotional system (above all the limbic system), and this results in an aesthetic experience in the receiver of a work of art. A strong emotional impact of works of art is also related to the stimulation of cognitive and emotional interest towards the presented figures. During contact with a work of art, a social simulation is induced in the viewer, and as a result he or she can draw somewhat fair conclusions regarding the intellectual and emotional states of the observed figures, as well as truly experience empathy for them (Eslinger, 1998). It can be assumed that during perception of artistic presentations of people, the visual information processing system is joined by the mirror neuron system, responsible for feeling empathy (Rizzolatti \& Craighero, 2004). 


\section{CURRENT STUDY}

Although the perception of a work of art is subject to the standard psychology and physiology laws, given that it concerns a special kind of stimulus (Ramachandran \& Hirstein, 1999), it can differ from the perception of non-artistic objects. In other words, the perception of artistic images of women presumably differs from that evoked in commercial pictures of women. The difference mainly concerns the emotional experiences. When looking at works of art, the viewer undergoes a special emotional-aesthetic experience (Ramachandran, 2011), while looking at images of women in print advertisements most often activates the processes of social comparison (Festinger, 1954), which, in return, lead, amongst others, to experiencing body-related fear and shame (Fredrickson \& Roberts, 1997). It could therefore be assumed that girls during adolescence, when their body image is most intensively shaped, would react differently to commercial images of women than to their artistic presentations. Distinct perceptions would probably be expressed though significantly different levels of (dis)satisfaction with their own body. The perception of print advertisements of women would have a negative influence on the attitude towards one's own body, expressed through: 1) a decreased level of body satisfaction (lowered acceptance towards one's own physical appearance), 2) increased level of body dissatisfaction (increased desire to change one's own body), and 3) change of emotions towards one's own body - intensification of negative emotions with the simultaneous weakening of positive ones (hypothesis 1 ). On the other hand, the perception of artistic presentations of women would not significantly amend the attitude towards one's own body, i.e. it would not negatively influence the levels of satisfaction or dissatisfaction with one's own body and would not weaken the positive, nor strengthen the negative emotions towards the body (hypothesis 2).

\section{METHOD}

\section{PARTICIPANTS}

The study group consisted of 140 girls, students of junior high schools in the NorthEastern part of Poland. All the respondents were randomly assigned to one of two groups. Each group contained 35 persons aged 13-14 and 35 aged 15-16 years old, 70 people in total. Both groups, A - print advertisement, and B - works of art, were relatively homogeneous in terms of demography (place of residence), BMI, following weight-loss diets, performing physical activity, as well as intensity of beauty care (see Table 1). 
Table 1. Demographic and clinical data

\begin{tabular}{|c|c|c|c|}
\hline \multirow{2}{*}{\multicolumn{2}{|c|}{ Demographic data }} & \multicolumn{2}{|c|}{$\begin{array}{c}\text { Number (and percentage) of surveyed girls } \\
\text { in a given group }\end{array}$} \\
\hline & & Group A & Group B \\
\hline \multirow{3}{*}{$\begin{array}{l}\text { Place of } \\
\text { residence }\end{array}$} & $>25,000$ inhabitants & 40 (57.1\%) & 46 (65.7\%) \\
\hline & $<25,000$ inhabitants & $23(32.9 \%)$ & $12(17.1 \%)$ \\
\hline & village & 7 (10\%) & $12(17.1 \%)$ \\
\hline \multirow{4}{*}{ BMI } & underweight $(<18.5)$ & 26 (37.1\%) & $28(40 \%)$ \\
\hline & normal (18.5-24.99) & 41 (58.6\%) & 39 (55.7\%) \\
\hline & overweight (25-29.99) & $2(2.9 \%)$ & $3(4.3 \%)$ \\
\hline & obese (>30) & $1(1.4 \%)$ & 0 \\
\hline \multirow{2}{*}{ Weight-loss diet } & following & $16(22.9 \%)$ & $10(14.3 \%)$ \\
\hline & not following & $54(77.1 \%)$ & 60 (85.7\%) \\
\hline \multirow{2}{*}{ Physical activity } & performing & $52(74.3 \%)$ & $59(84.3 \%)$ \\
\hline & not performing & $18(25.7 \%)$ & $11(15.7 \%)$ \\
\hline \multirow{3}{*}{ Beauty care } & $<1$ hour daily & $14(20 \%)$ & $18(25.7 \%)$ \\
\hline & 1-2 hours daily & 43 (61.4\%) & 38 (54.3\%) \\
\hline & $>2$ hours daily & 13 (18.6\%) & $14(20 \%)$ \\
\hline
\end{tabular}

\section{MEASUREMENTS}

\section{BODY SATISFACTION}

In order to determine changes in body satisfaction as a result of looking at one of both experimental materials: 1) magazine advertising, or 2) works of art, the Body Satisfaction Questionnaire was employed. The scale consists of 7 items, which refer to general body satisfaction (item examples: "Q2. I feel attractive", “Q6. I like my mirror image”). The analysis of the internal scale structure with the use of the Exploration Factor Analysis revealed one factor explaining 85.39\% of the results' variation. Factor loadings of particular items take values from 0.89 to 0.94 . Cronbach's alpha is very high, at 0.96 .

\section{BODY DISSATISFACTION}

The 4-item Body Dissatisfaction Scale was employed to define the change in body dissatisfaction intensity that took place after seeing the experimental materials. Items refer to general dissatisfaction with subjects' own external appearance, expressed mostly through the need for its modification and change. An example of an item: "I feel that I must work on my physical appearance". The analysis of the 
internal scale structure with the use of the Exploration Factor Analysis revealed one factor explaining $69.97 \%$ of the results' variation. Factor loadings of particular items take values from 0.81 to 0.87 . Cronbach's alpha is at 0.85 .

Both questionnaires were employed twice: before and after seeing the experimental materials. The task of every respondent was to refer to each item through marking a point on a 100-milimeter line with I strongly disagree or I strongly agree.

\section{BODY EMOTION}

The change in the general state of positive and negative emotions towards subjects' own bodies was also examined. Before being shown the experimental materials the respondents were asked to refer to two statements: 1) "When I look at myself I usually experience positive emotions towards my own body”, and 2) "When I look at myself, I usually experience negative emotions towards my own body". The respondents were asked to mark the intensity of the experienced emotions on a scale (from 1 - very weak to 5 - very strong). Then, after seeing the experimental materials, the respondents defined the changed emotions towards their body (positive and negative) under the influence of the shown images of women. In order to do that, they referred to the following statements: 1) "While looking at images of women I felt positive emotions towards my own body", and 2) "While looking at images of women I felt negative emotions towards my own body". Again, they assessed the strength of the experienced emotions on a 5-point scale.

\section{OBJECTIFIED BODY CONSCIOUSNESS}

The Objectified Body Consciousness Scale (OBCS) (McKinley \& Hyde, 1996) was employed in order to define the level of self-objectification of teenage girls. The method consists of 24 test items, evaluated on a 7-point scale and grouped in 3 sub-scales: 1) body surveillance, 2) body shame, and 3) appearance control beliefs. The respondents completed the OBCS questionnaire once before being shown the experimental materials.

\section{DEMOGRAPHIC FORM}

The main demographic data (amongst others, age, place of residence, weight, height, etc.) was collected through a paper-and-pencil demographic questionnaire.

\section{EXPERIMENTAL MANIPULATION}

In the research two types of experimental materials were used. At the beginning, a starting pool of images was collected, which was then evaluated by competent 
judges, based on strictly defined criteria. The first part of the experimental material, "Women in magazine advertising”, was to include such photographs extracted from women's colour press that presented a perfect woman, according to the currently prevailing social standards. The advertisements that did not fulfil those criteria, i.e. reached a score below 6 on a 7-point scale, were rejected. The second material contained works of art presenting images of women ("Women in works of art”). The aim was to include artistic presentations of women created throughout the ages and as diverse as possible.

\section{WOMEN IN MAGAZINE ADVERTISING}

The first experimental material consisted of images of women with perfect shapes and proportions, appearing in perfume advertisements in colour press for women. Amongst them, pictures of women from the following perfume advertisements were included: Jimmy Choo, Kate Moss Vintage, Beyoncé Heat, Britney Spears Radiance, and Paris Hilton. Altogether, 38 pictures were used. Each of them was displayed for 8 seconds, and the projection of all lasted ca. 5 minutes. The final experimental material consisted of two rounds of displaying the same pictures, forming a 10 -minute presentation.

\section{WORKS OF ART}

In the second part of the experimental material, works of art showing very diverse images of women were used, originating from different periods: starting from antiquity, through the Middle Ages, the Renaissance, the Baroque, Romanticism, up until the 20th century. Amongst them were included such masterpieces as: Aphrodite of Cnidus, Queen Nefertiti, Portrait of a Lady by Rogier van der Weyden, Mona Lisa by Leonardo da Vinci, The Three Graces by Peter Paul Rubens, The Nude Maja by Francisco Goya, Lady Lilith by Dante G. Rossetti, or Blue Dancers by Edgar Degas. In total, 38 paintings were chosen. Each of them was displayed for 8 seconds, and the projection of all lasted ca. 5 minutes. The final experimental material consisted of two rounds of displaying the same paintings, and lasted 10 minutes.

\section{PROCEDURE}

The study consisted of three parts. In the first one the teenage girls received an envelope in which they could find the demographic form and the questionnaires (The Body Satisfaction Questionnaire, The Body Dissatisfaction Scale, and The Objectified Body Consciousness Scale, as well as two items concerning bodyrelated emotional state). Once the test material was completed, the second part of 
the study began. Depending on the randomly chosen group, A or B, a 10-minutelong presentation of images of women in advertisement for group A, and of artistic images of women for group B took place. Immediately after the presentation was terminated, the third part of the study commenced, i.e. the final measure of the manipulated dependent variable. In other words, the respondents once more completed the Body Satisfaction Questionnaire and the Body Dissatisfaction Scale, and referred to two items concerning the change in their emotional state related to the observed images of women. The whole study took on average 35-45 minutes. The study was conducted in 2015.

\section{RESULTS}

The data analysis was started by verifying the groups' homogeneity in terms of the level of body objectification and indicators of body (dis)satisfaction, measured before the presentation of the experimental material (see Table 2). The obtained data showed that groups A and B did not vary significantly from each other in the general OBSC result and in individual self-objectification indicators: body surveillance, body shame and appearance control beliefs. The groups were also similar in terms of initial body satisfaction, body dissatisfaction, and negative body emotion. On the other hand, they differed notably in terms of positive body emotion, which turned out to be much weaker in group A.

Table 2. A comparison of scores obtained in the variables by the groups: ANOVA

\begin{tabular}{|l|c|c|c|c|c|c|}
\hline \multirow{2}{*}{\multicolumn{1}{|c|}{ Variables }} & \multicolumn{2}{c|}{$\begin{array}{c}\text { Group A } \\
\mathrm{N}=70\end{array}$} & \multicolumn{2}{c|}{$\begin{array}{c}\text { Group B } \\
\mathrm{N}=70\end{array}$} & \multicolumn{2}{c|}{$\begin{array}{c}\text { Significance } \\
\text { of differences }\end{array}$} \\
\cline { 2 - 7 } & $M$ & $S D$ & $M$ & $S D$ & $F(1,138)$ & $p$ \\
\hline Body Satisfaction & 310.14 & 205.74 & 341.90 & 191.56 & 0.89 & $\mathrm{~ns}$ \\
\hline Body Dissatisfaction & 272.07 & 99.20 & 244.28 & 104.11 & 2.61 & $\mathrm{~ns}$ \\
\hline Positive Body Emotion & 1.64 & 1.83 & 2.40 & 2.05 & 5.30 & 0.02 \\
\hline Negative Body Emotion & 2.47 & 1.66 & 2.34 & 1.78 & 0.19 & $\mathrm{~ns}$ \\
\hline $\begin{array}{l}\text { Objectified Body } \\
\text { Consciousness }\end{array}$ & 109.71 & 16.76 & 105.17 & 15.40 & 2.79 & $\mathrm{~ns}$ \\
\hline Body surveillance & 38.00 & 7.04 & 35.58 & 8.84 & 3.19 & $\mathrm{~ns}$ \\
\hline Body shame & 32.61 & 9.95 & 31.28 & 10.27 & 0.60 & $\mathrm{~ns}$ \\
\hline $\begin{array}{l}\text { Appearance control } \\
\text { beliefs }\end{array}$ & 39.10 & 6.56 & 38.30 & 6.74 & 0.51 & $\mathrm{~ns}$ \\
\hline
\end{tabular}


Statistical analyses were also performed for Pearson's correlation coefficients between self-objectification indicators and the variables: body satisfaction, body dissatisfaction, positive body emotion and negative body emotion in the whole study group $(\mathrm{N}=140$ ) before introducing the experimental stimulus (see Table 3). The correlations between two self-objectification indicators (body surveillance and body shame) and all the body (dis)satisfaction variables proved to be significant. It was especially the correlation between body shame and body satisfaction, as well as the correlation between shame and body dissatisfaction that revealed a strong link between the variables. In the first case, high values of body shame were accompanied by low values of body satisfaction, while in the second case - high values of body shame correlated with high values of body dissatisfaction. On the other hand, the correlations proved to be insignificant between body control and body (dis)satisfaction variables.

Table 3. Pearson's correlation coefficients for relationships between the objectified body consciousness variables and (dis)satisfaction body variables $(N=140)$

\begin{tabular}{|c|c|c|c|c|}
\hline & $\begin{array}{c}\text { Body satisfac- } \\
\text { tion }\end{array}$ & $\begin{array}{l}\text { Body dissatis- } \\
\text { faction }\end{array}$ & $\begin{array}{c}\text { Positive } \\
\text { body emotion }\end{array}$ & $\begin{array}{c}\text { Negative } \\
\text { body emotion }\end{array}$ \\
\hline Body surveillance & $\begin{array}{c}-0.45^{* *} \\
.001\end{array}$ & $\begin{array}{c}0.49 * * \\
.001\end{array}$ & $\begin{array}{c}-0.32 * * \\
.001\end{array}$ & $\begin{array}{c}0.36^{* *} \\
.001\end{array}$ \\
\hline Body shame & $\begin{array}{c}-\mathbf{0 . 6 3} 3^{* *} \\
.001\end{array}$ & $\begin{array}{c}\mathbf{0 . 6 4 ^ { * * }} \\
.001\end{array}$ & $\begin{array}{c}-0.49 * * \\
.001\end{array}$ & $\begin{array}{c}0.39 * * \\
.001\end{array}$ \\
\hline Control over body & ns & ns & ns & ns \\
\hline
\end{tabular}

${ }^{* *} p<0.01$

In order to verify the hypothesis regarding the negative influence of the perception of images of women in press advertisements on the body attitude, and the positive influence of images of women in art, the ANOVA variance analysis within-subject variables was performed.

The analysis performed with Student's t-test for dependent samples revealed that the perception of magazine representations of women significantly influenced body satisfaction $(d$ Cohen $=0.34)$ and positive body emotion $(d$ Cohen $=0.41)$. Before employing the experimental material (presentation of women in press advertisements), the average of general body satisfaction in group A was significantly higher $(M=310.14, S D=205.74)$ than after the presentation $(M=284.60$, $S D=215.88$ ). Similarly, the average of positive body emotion before looking at images of women in advertisements $(M=1.64, S D=1.83)$ was higher than afterwards $(M=0.78, S D=1.60)$. In the case of the influence of images of women in 
Table 4. Comparison of body (dis)satisfaction before and after the presentation of magazine advertising (group A) and works of art (group B) measured by ANOVA variance analysis within-subject variables

\begin{tabular}{|c|c|c|c|c|c|c|}
\hline & \multicolumn{2}{|c|}{$\begin{array}{c}\text { Differences } \\
\text { in dependent samples }\end{array}$} & \multicolumn{3}{|c|}{$\begin{array}{l}\text { Significance } \\
\text { of differences }\end{array}$} \\
\hline & & $M$ & $S D$ & $t$ & $d f$ & $p$ \\
\hline $\begin{array}{l}\text { Group A } \\
\text { Pair 1: }\end{array}$ & $\begin{array}{l}\text { pre-body satisfaction, } \\
\text { post-body satisfaction }\end{array}$ & 25.54 & 74.49 & 2.87 & 69 & .01 \\
\hline Pair 2: & $\begin{array}{l}\text { pre-body dissatisfaction, } \\
\text { post-body dissatisfaction }\end{array}$ & 10.83 & 59.75 & 1.52 & 69 & ns \\
\hline Pair 3: & $\begin{array}{l}\text { pre-positive body emotions, } \\
\text { post-positive body emotions }\end{array}$ & 0.86 & 2.07 & 3.47 & 69 & .001 \\
\hline Pair 4: & $\begin{array}{l}\text { pre-negative body emotions, } \\
\text { post-negative body emotions }\end{array}$ & -0.07 & 1.79 & -0.33 & 69 & ns \\
\hline $\begin{array}{l}\text { Group B } \\
\text { Pair 1: }\end{array}$ & $\begin{array}{l}\text { pre-body satisfaction, } \\
\text { post-body satisfaction }\end{array}$ & -44.67 & 73.38 & -5.09 & 69 & .001 \\
\hline Pair 2: & $\begin{array}{l}\text { pre-body dissatisfaction, } \\
\text { post-body dissatisfaction }\end{array}$ & 32.43 & 63.29 & 4.29 & 69 & .001 \\
\hline Pair 3: & $\begin{array}{l}\text { pre-positive body emotions, } \\
\text { post-positive body emotions }\end{array}$ & 0.47 & 2.34 & 1.68 & 69 & ns \\
\hline Pair 4: & $\begin{array}{l}\text { pre-negative body emotions, } \\
\text { post-negative body emotions }\end{array}$ & 1.76 & 2.03 & 7.23 & 69 & .001 \\
\hline
\end{tabular}

works of art, the average of body satisfaction before the presentation ( $M=341.90$, $S D=191.56)$ was significantly lower than afterwards $(M=386.57, S D=213.07$; $d$ Cohen $=0.61$ ). Accordingly, the average body dissatisfaction before seeing artistic images of women $(M=244.28, S D=104.11)$ was significantly higher than after $(M=211.86, S D=113.72)$, $(d$ Cohen $=0.51)$. Similarly, the average of negative body emotion before the exposition of experimental material $(M=2.34, S D=1.78)$ was significantly higher than afterwards $(M=0.58, S D=1.46)$. The value of $d$ Cohen $=0.87$ suggested a strong influence of the artistic presentations of women on weakening the level of negative body emotion.

In order to verify whether there are notable differences in body satisfaction and dissatisfaction, as well as in experiencing negative body emotions after the presentation of the experimental materials in groups A (looking at magazine images of women) and B (looking at artistic images of women), a univariate ANOVA vari- 
ance analysis in independent groups was performed. As a result of those analyses, a statistically significant effect was obtained in the following variables: body satisfaction $\left(F(1,138)=7.91, p=.01, \eta^{2}=.05\right)$, body dissatisfaction $(F(1,138)=7.14$, $\left.p=.001, \eta^{2}=.05\right)$, and negative body emotion $\left(F(1,138)=42.59, p<.001, \eta^{2}=.23\right)$. This means that body satisfaction increased much more intensively after the presentation of the experimental material in subjects in group $B$, to whom works of art were shown $(M=386.57, S D=213.07)$, compared to group A, who were looking at press advertisement images of women $(M=284.60, S D=215.88)$. At the same time, body dissatisfaction was notably lower in group $\mathrm{B}(M=211.86, S D=113.72)$ than in group A $(M=261.24, S D=104.70)$, as were negative body emotions in group B $(M=0.58, S D=1.46)$, compared to group A $(M=2.54, S D=2.04)$.

The differences in experiencing positive body emotions after seeing the experimental materials were not analysed in view of the lack of the homogeneity of both groups in terms of this variable before the start of the study.

\section{DISCUSSION}

The experimental study performed on a group of adolescent girls demonstrated the negative influence of press advertisements on their body satisfaction. The obtained results have confirmed the assumption that the perception of press advertisement images of women would significantly change teenagers' attitude towards their own body (hypothesis 1). A 10-minute-long exposition of the advertisement materials significantly lowered body satisfaction and weakened positive body emotion. On the other hand, the presentation of artistic images of women not only did not negatively influence the level of body satisfaction, did not weaken positive or strengthen negative body emotion (hypothesis 2), but also had a relevant positive effect on the teenage girls' body attitude. Above all, it increased the level of body satisfaction in teenage girls, lowered their body dissatisfaction, and weakened negative body emotion. The positive verification of the first hypothesis is coherent with the results of former studies on the influence of press advertisements on body dissatisfaction in teenage girls (Groesz et al., 2002; Ferguson, 2013).

To our knowledge, no former studies explored the influence of images of women in works of art on teenage girls' body attitude. The present study is the first to examine whether and how artistic representations of women influence a teenage viewer. The comparison between both study groups in terms of experimentally changed body (dis)satisfaction revealed that teenage girls from the second group, to whom artistic representations of women were shown, demonstrated a notably 
higher level of body satisfaction, a significantly lower level of body dissatisfaction, and a considerably weaker intensity of negative body emotion than the persons from the first group, who looked at press advertisement images of women. This means that the same amount of time, a 10-minute exposition to images of women, depending on the form of presentation, advertisement or artistic, considerably changed their body attitude. In the case of the perception of press advertisement representations of women, based on such attributes as youth, slimness and beauty (Grogan, 2008; Silberstein et al., 1986), teenage girls experienced a significant lowering of positive body emotion. It can be assumed that in accordance with the objectified body consciousness theory (Fredrickson \& Roberts, 1997), the unrealistic images of women, most often digitally retouched, and therefore impossible to achieve in reality (Kilbourne, 2002; Tyler et al., 2009), triggered in them the processes of social comparison (Festinger, 1954), and in consequence strong feelings of shame and fear. The higher the initial level of self-objectification (in the dimensions of body surveillance and body shame) that characterised the respondent before the study (see Table 3), the stronger those feelings were. On the other hand, looking at artistic representations of women, which forced the viewer to step outside of the conventional reception and to undertake intense perceptive interpretation (Ramachandran, 2011), significantly weakened negative body emotion in the study group. Presumably, in the case of contact with a work of art, the viewer's attention was absorbed by the artist's "hints", so that the perceptive system was intensively alert, and as a result the emotional system along with the limbic system, being its main link, was also strongly activated (Zeki, 2004). In other words, the teenagers taking part in the study did not compare themselves with the observed women, but instead participated in an aesthetic experience. As a result, they concentrated less on their body and the way they looked, and instead engaged in the experiences of the presented women - their emotions, feelings and needs. Through the identification with the characters (women) presented in the works of art, the teenage girls participated to a certain extent in their subjectivity. The system of aesthetic-empathic experiences, activated through contact with works of art, presumably reflexively increased sensitivity to the states of the subject herself, at the same time contributing to the weakening of self-objectification, and hence the weakening of negative body emotion and increasing body satisfaction.

The obtained results suggest that the perception of press advertisement images of women significantly differs from the perception of artistic representations of women. In the first case, the viewer's attention is directed at the models' perfect shapes, which predominate over the personal aspect in commercial photography. It is the body itself, its shape and size, and not the subject in a given moment of 
her existence that matter most. Presumably, the mirror neurons system is significantly weakened at the same time. It is inhibited by fear and shame (Rizzolatti \& Craighero, 2004), which emerge as the result of a subject comparing herself to an idealised woman from a commercial photograph.

On the other hand, works of art, thanks to artistic devices that, among others, allow a very peculiar manner of managing the attention, intensify the receiver's emotional-aesthetic experience. According to Ramachandran (2011), they employ a language anchored in the right hemisphere, which is unknown or even strange to the left one, famous for its literalness. The ambiguity of a high order present in works of art allows the experiencing of the images of women in many different ways, which is usually aesthetically pleasant (Zeki, 2004). To do that, complex imagination processes are necessary, and photography, given its literalness, almost completely rules them out. Nonetheless, presumably the most important aspect is that the mirror neurons system is activated during exposure to works of art, which allows the experiencing of the image of a woman as a subject, and not an object. Contrary to the perception of press advertisement images of women, the reception of artistic images of women is probably not limited to the sole identification of an object based on the traits of external looks, but widens its perception to the subjectivity dimension. As a result, the observed woman appears as an individual, and not an object to be analysed or a benchmark against which the objectified body of a receiver can be compared. Since the artist, as an "unaware neurobiologist", can activate a set of neurophysiological processes in the receiver's brain, as well as feelings of aesthetic awe and sense of beauty (Ramachandran \& Hirstein, 1999), most probably the receiver of his or her work - a teenage girl looking at artistic presentations of women - participates in a process of self-awareness change, consisting in a weakening of self-objectification for the benefit of strengthening of the self, which can be reflected in a positive body attitude.

\section{IMPLICATIONS AND SUMMARY}

The positive influence of the perception of artistic images of women on teenage girls' body satisfaction revealed in the study gives a suggestion of how to protect young girls from the oppressive influence of mass media. It appears that it is not solely about learning how to receive advertisements and acquiring the ability to critically address the messages included in commercial communication that can protect teenage girls from the threatening negative changes in their body image. A similar, preventive and still unrecognised role can successfully be performed 
by works of art, especially the artistic presentation of women. Women from the paintings of Titian, Sandro Botticelli, Peter Paul Rubens or other great masters can strengthen the resistance to self-objectification processes in teenage girls and develop awareness of the self as a subject, indispensable in shaping identity during the period of adolescence. Therefore, it would be beneficial to include lessons on getting to know works of art in school education, during which teenagers could acquire the skills necessary to receive and experience painting and sculpture, i.e. to enter into contact with the aesthetic worlds created by artists.

\section{References}

American Psychiatric Association (1994). Diagnostic and statistical manual of mental disorders, Fourth Edition. Washington, DC.

Dittmar, H., \& Howard, S. (2004). Thin-ideal internalization and social comparison tendency as moderators of media models' impact on women's body-focused anxiety, Journal of Social and Clinical Psychology, 23, pp. 768-791.

Eisenberg, M.E., Neumark-Sztainer, D., \& Paxton, S. (2006). Five-year change in body satisfaction among adolescents, Journal of Psychosomatic Research, 61, pp. 521-527.

Fredrickson, B.L., \& Roberts, T.A. (1997). Objectification theory: Toward understanding women's lived experiences and mental health risks, Psychology of Women Quarterly, 21(2), pp. 173-206.

Ferguson, C. J. (2013). In the eye of the beholder: Thin-ideal media affects some, but not most, viewers in a meta-analytic review of body dissatisfaction in women and men, Psychology of Popular Media Culture, 2, pp. 20-37.

Festinger, L. (1954). A theory of social comparison processes, Human Relations, 7, pp. 117140.

Gombrich, E.H. (1984). Art and Illusion. New York: Princeton University Press, p. 71.

Groesz, L.M., Levine, M.P., \& Murnen, S.K. (2002). The effect of experimental presentation of thin media images on body satisfaction: A meta-analytic review, International Journal of Eating Disorders, 31, pp. 1-16.

Grogan, S. (2008). Body image. Understanding body dissatisfaction in men, women and children. London: Poutledge.

Halliwell, E., \& Dittmar, H. (2006). Associations between appearance-related self-discrepancies and young women's and men's affect, body image, and emotional eating: A comparison of fixed-item and respondent self-discrepancy measures, Personality and Social Psychology Bulletin, 32, pp. 447-458.

Hargreaves, D.A., \& Tiggemann, M. (2004). Idealized media images and adolescent body image: “Comparing” boys and girls, Body Image, 1, pp. 351-361.

Jones, D.C. (2004). Body image among adolescent girls and boys: A longitudinal study, Developmental Psychology, 115, pp. 119-125.

Jones, D.C., \& Crawford, J. K. (2005). Adolescent boys and body image: Weight and muscularity concerns as dual pathways to body dissatisfaction, Journal of Youth and Adolescence, 34, pp. 629-636. 
Kilbourne, J. (2002). Killing us softly. Advertising's image of women, Media Education Foundation: USA.

Knauss, S., Paxton, S.J., \& Alsaker, F.D. (2007). Relationships amongst body dissatisfaction, internalization of the media body ideal and perceived pressure from media in adolescent girls and boys, Body Image, 4, pp. 353-360.

Knauss, S., Paxton, S.J., \& Alsaker, F.D. (2008). Body dissatisfaction in adolescent boys and girls: Objectified body consciousness, internalization of the media body ideal and perceived pressure from media, Sex Roles, 59, pp. 633-643.

Levine, M. P., \& Murnen, S. K. (2009). “Everybody knows that mass media are/are not [pick one] a cause of eating disorders": A critical review of evidence for a causal link between media, negative body image, and disordered eating in females, Journal of Social and Clinical Psychology, 28(1), pp. 9-42.

Lewis, M. (1992). Shame: The exposed self. New York: Free Press.

Lindberg, S.M., Hyde, J.S., \& McKinley, N.M. (2006). A measure of objectified body consciousness for preadolescent and adolescent youth, Psychology of Women Quarterly, 30, pp. 65-76.

Markey, C. N. (2010). Invited commentary: Why body image is important to adolescent development, Journal of Youth and Adolescence, 39, pp. 1387-1391.

Martin, M.C., \& Gentry, J.W. (1997). Stuck in the model trap: The effect of beautiful models in ads on female pre-adolescents and adolescents, The Journal of Advertising, 26, pp. 19-33.

McKinley, N. M., \& Hyde, J. S. (1996). The objectified body consciousness scale: development and validation, Psychology of Women Quarterly, 20, pp. 181-215.

Melosik, Z. (1996). Tożsamość, ciało i władza. Teksty kulturowe jako (kon)teksty pedagogiczne. Poznań-Toruń: Wydział Studiów Edukacyjnych UAM.

Myers, P.N., \& Biocca, F.A. (1992). The elastic body image: The effect of television advertising and programming on body image distortions in young women, Journal of Communication, 42, pp. 108-133.

Polivy, J., \& Herman, C.P. (2002). Causes of eating disorders, Annual Review of Psychology, 53, pp. 187-213.

Presnell, K., Bearman, S.K., \& Stice, E. (2004). Risk factors for body dissatisfaction in adolescent boys and girls: a prospective study, International Journal of Eating Disorders, 36, pp. 389-401.

Ramachandran, V.S. (2011/2012). The Tell-Tale Brain. A Neuroscientist's Quest for What Makes Us Human. Tłum. A. M. Binderowie, E. Józefowicz. Warszawa: Wydawnictwo Uniwersytetu Warszawskiego.

Ramachandran, V.S., \& Hirstein, W. (1999). The science of art. A neurological theory of aesthetic experience, Journal of Consciousness Study, 6 (6-7), pp. 15-51.

Rizzolatti, G. \& Craighero, L. (2004). The mirror-neuron system, Annual review of Neuroscience, 27, pp. 169-192.

Rodin, J., Silberstein, L., \& Striegel-Moore, R. (1985). Women and the weight: A normative discontent. In: T. B. Sonderegger (Ed.), Psychology and Gender (pp. 267-309). Lincoln: University of Nebraska Press.

Rosenblum, G.D., \& Lewis, M. (1999). The relations among body image, physical attractiveness, and body mass in adolescence, Child Development, 70, pp. 50-64. 
Silberstein, B., Perdue, L., Peterson, B., \& Kelly, F. (1986). The role of the mass media in promoting a thin standard of bodily attractiveness for women, Sex Roles, 14, pp. 519-532.

Smolak, L. (2004). Body image in children and adolescents: Where do we go from here?, Body Image, 1, pp. 15-28.

Thompson, J.K., Heinberg, L.J., Altabe, M., \& Tantleff-Dunn, S. (1999). Exacting Beauty: Theory, Assessment, and Treatment of Body Image Disturbance. Washington: American Psychological Association.

Tiggemann, M. (2005). Television and adolescent body image; The role of program content and viewing motivation, Journal of Social and Clinical Psychology, 24, pp. 361-381.

Tiggemann, M., \& Slater, A. (2004). Thin ideals in music television: A source of social comparison and body dissatisfaction, International Journal of Eating Disorders, 35, pp. 48-58.

Tyler, K., Lopez, S., \& Flores, L. (2009). The media, body evaluation, and perceptions of physical attractiveness among college-aged women and men, Psi Chi Journal of Undergraduate Research, 14 (1), pp. 25-33.

Zeki, S. (2004). The neurology of ambiguity, Journal of Consciousness and Cognition, 13, pp. 173-196. 